\title{
A comprehensive analysis on the relationships between elastic wave velocities and petrophysical properties of sedimentary rocks based on laboratory measurements
}

\author{
Siddharth Garia ${ }^{1} \cdot$ Arnab Kumar Pal $^{1} \cdot$ K. Ravi $^{1} \cdot$ Archana M. Nair $^{1}$ (D)
}

Received: 24 May 2018 / Accepted: 6 May 2019 / Published online: 14 May 2019

(c) The Author(s) 2019

\begin{abstract}
This paper is an attempt to find the interdependence existing between petrophysical properties and ultrasonic wave velocities. Porosity and permeability, apart from other properties, are the two fundamental physical properties of rock responsible for storing and producing hydrocarbon. Understanding the elastic properties of such rocks is essential in developing a deep understanding about the rock and fluid models that describe the seismic response to realistic hydrocarbon reservoirs under different environmental conditions. Therefore, in this study, a detailed state-of-the-art review of the existing association between compressional and shear wave (also known as $\mathrm{P}$ wave and $\mathrm{S}$ wave) velocities $\left(V_{\mathrm{p}}\right.$ and $\left.V_{\mathrm{s}}\right)$ and different petrophysical properties (porosity, density, permeability, water absorption and clay content) has been summarized for carbonate and sandstone rock types of different regions. The relationships discussed are based on datasets measured in laboratory by various researchers under ambient conditions. An effort is made to propose a general trend (global trends) for porosity versus $V_{\mathrm{p}}$ and bulk density versus $V_{\mathrm{p}}$, which is independent of the type of datasets. However, it is clear that trends do exist, but the prediction is difficult. The empirical relationships derived by various researchers are valid only to the particular dataset for which the relationship was derived. The influence of other factors like mineralogy, rock framework, pore geometry has not been studied by the researchers in their respective studies. Nevertheless, these relationships and correlations can be useful in hydrocarbon exploration industry where direct measurements may not be possible. Moreover, an accurate reservoir description can only be achieved by the integration of geological, petrophysical and geotechnical data.
\end{abstract}

Keywords Compressional wave $\cdot$ Shear wave $\cdot$ Porosity $\cdot$ Permeability

$\begin{array}{ll}\text { List of symbols } \\ V_{\mathrm{p}} & \text { P-wave velocity } \\ V_{\mathrm{s}} & \text { S-wave velocity } \\ \rho & \text { Density } \\ n & \text { Porosity } \\ n^{\prime} & \text { Effective porosity } \\ \rho_{\text {dry }} & \text { Dry density } \\ \rho_{\text {sat }} & \text { Saturated density } \\ \rho_{\text {bulk }} & \text { Bulk density } \\ \rho_{\text {fluid }} & \text { Density of fluid } \\ W_{\mathrm{a}} & \text { Water absorption } \\ C & \text { Clay content } \\ t & \text { Transit time }\end{array}$

Archana M. Nair

nair.archana@iitg.ac.in

1 Department of Civil Engineering, Indian Institute of Technology, Guwahati 781039, India

$$
\begin{array}{ll}
L & \text { Length of Specimen } \\
k & \text { Permeability } \\
w_{\text {sat }} & \text { Saturated weight } \\
w_{\text {dry }} & \text { Dry weight } \\
w_{\text {sub }} & \text { Submerged weight }
\end{array}
$$

\section{Introduction}

The recovery from unconventional energy fields such as tight oil and gas fields, coal bed methane, shale gas and sustainable energy management practices such as carbon sequestration in the past decade has given rise to new opportunities (Chengzao 2017) and challenging technical innovation in the petroleum industry. These new opportunities resulted in a greater focus on rock properties and reservoir heterogeneities that affect the reservoir performance. Reservoir rocks, being the end-product of a series of complex geological and hydrodynamical processes like sedimentation, compaction 
and diagenesis (Dvorkin et al. 2014), are characterized by complex pore space geometry. These complex pore structures control the associated petrophysical properties like porosity, permeability and related seismic velocity. Understanding the elastic properties of such rocks is quite challenging due to the heterogeneity and complexity of their structures. During the prospecting phase of any reservoir (conventional or unconventional), subsurface geological and petrophysical evaluation is predominantly based on seismic data. Seismic data provide a structural image of the subsurface that depends on various parameters such as lithology, porosity, type of fluid, pressure and temperature (Yu et al. 2016). These data help in delivering the information about different petrophysical properties like density and porosity. Hence, it is essential to correctly understand the relationship between the seismic, petrophysical and the geological properties in order to correctly predict the reservoir characteristics from the seismic attributes. Many researchers Assefa et al. (2003), Kahraman and Yeken (2008), Kassab and Weller (2015), Al-Dousari et al. (2016) and Pappalardo and Mineo (2016) have conducted studies relating the compressional and shear wave velocities with the petrophysical properties of sedimentary rocks by using different laboratory techniques based on ultrasonic velocity measurements.

Ultrasonic velocity measurement techniques have been used by researchers McDowell and Millett (1984), Han et al. (1986), Gaviglio (1989), Klimentos (1991), Yasar and Erdogan (2004), Kahraman (2007), Sharma and Singh (2008), Kahraman and Yeken (2008), Kilic and Teymen (2008), Sarkar et al. (2012) and Madhubabu et al. (2016) across the literature to determine the compressional and shear wave velocities of various rock samples in laboratory. The advantage of ultrasonic method of measurement is that it is simple, fast, economic and nondestructive in nature (Moradian and Behnia 2009). Thus, it can be used in field as well as in laboratory and hence used widely in civil, mining and geotechnical engineering. The main idea of this paper is to explore a link between physical properties and elastic properties that can help in developing a deep understanding about the rock and fluid models that define the seismic response to realistic hydrocarbon reservoirs.

The understanding and quantification of rock elastic wave velocity variations are significant to extract petrophysical properties from seismic attributes. As there exists a large variation in the actual measurement of compressional and shear wave velocities, several models exist on the relationship between seismic data and petrophysical properties. Different researchers established that the compressional and shear wave velocities depend on various petrophysical properties like porosity, density, water absorption, clay content, saturating fluid and permeability. Compressional and shear wave velocities may increase or decrease depending on different parameters since one-to-one relationship between the properties is not yet established. Hence, the objective of this paper is to analyze the state-of-the-art research conducted by different researchers in laboratory-scale measurements of various reservoir rock types on compressional and shear wave velocities and their dependency on petrophysical properties.

Due to different arrangement (packing) and composition of grains, there are differences in density, porosity and permeability as a result of which there are differences in compressional and shear wave velocity. Many researchers have conducted studies relating the compressional and shear wave velocities with the petrophysical properties by different laboratory techniques for measuring ultrasonic wave velocity as mentioned in Table 1 and observed that there exists a definite relation between them. For example, $V_{\mathrm{p}}$ increases with a decrease in porosity, while $V_{\mathrm{p}}$ increases with an increase in density, but the scattering of data indicates that the influence of factors like rock framework and mineralogy must also need to be considered while evaluating the relationship between them. Moreover, the higher the density, the lower the porosity, and thus, the higher the $V_{\mathrm{p}}$ (Gaviglio 1989; Yasar and Erdogan 2004; Kahraman and Yeken 2008; Soroush et al. 2011; Sarkar et al. 2012; Kassab and Weller 2015; Parent et al. 2015; Kurtulus et al. 2016; Sayed et al. 2015; Al-Dousari et al. 2016). Thus, there exists an interdependence between the petrophysical properties and compressional and shear wave velocities. Various researchers have tried to establish these interdependencies with respect to the experimental datasets measured under ambient as well as stressed conditions. It is an established fact that ultrasound compressional and shear wave velocities are effected by stress conditions. Hence, to analyze the interdependencies of various petrophysical parameters on $V_{\mathrm{p}}$ and $V_{\mathrm{s}}$, it is healthier to use datasets measured under ambient conditions. The present paper thus focuses on the datasets available in the literature measured for sandstones and carbonates under ambient conditions.

\section{Methodology}

In the present study, an attempt is made to correlate the variation in compressional and shear wave velocities $\left(V_{\mathrm{p}}\right.$ and $V_{\mathrm{s}}$ ) of different sedimentary rocks with respect to different petrophysical parameters such as porosity, density, water absorption, clay content and permeability. In order to include a wide range of datasets for a comprehensive analysis, datasets used in this paper are generated by various researchers from laboratory experiments conducted on sandstones, carbonates and other sedimentary rocks such as mudstone and shale under ambient conditions. The present paper used only reported datasets generated from experimental measurements under ambient conditions so as to have 


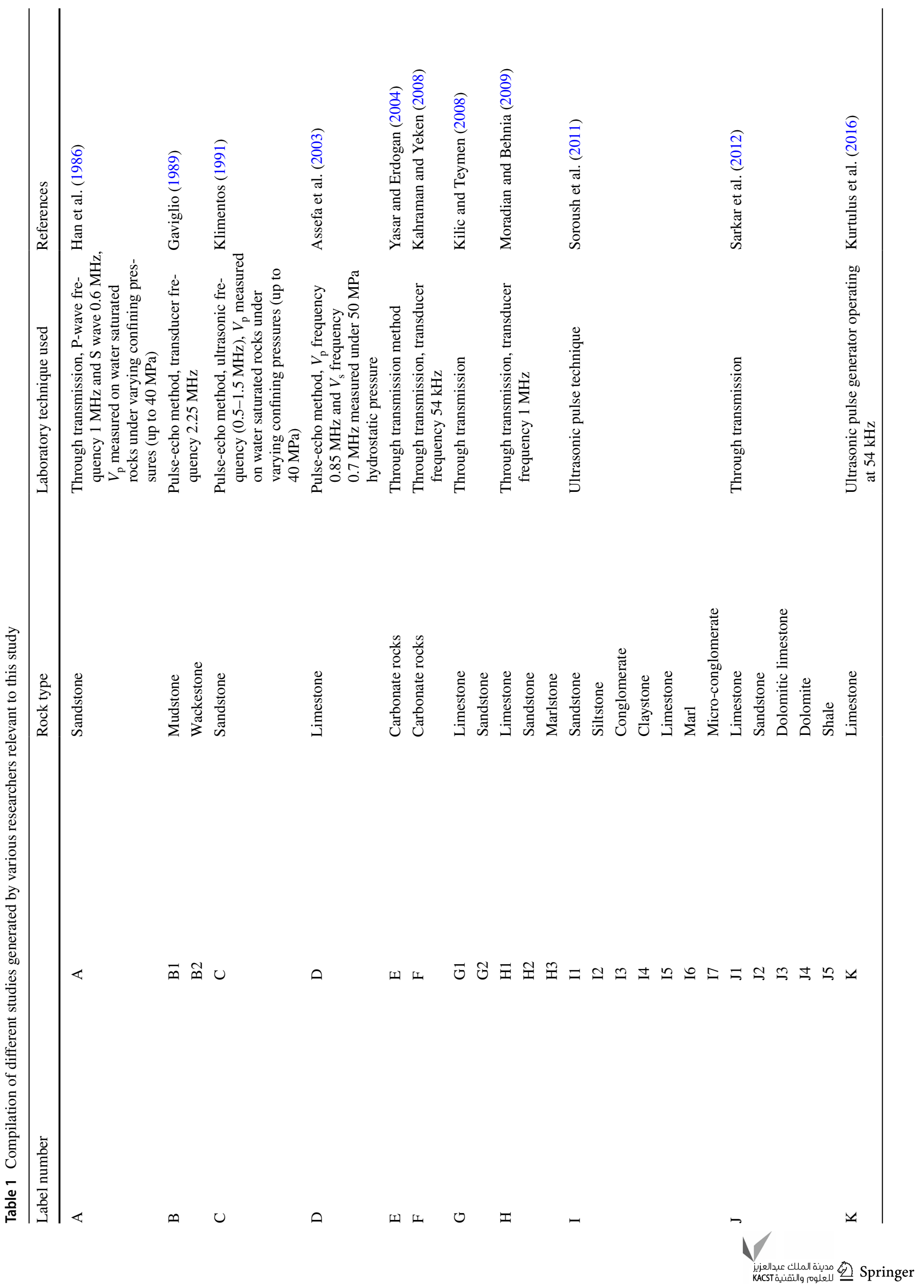




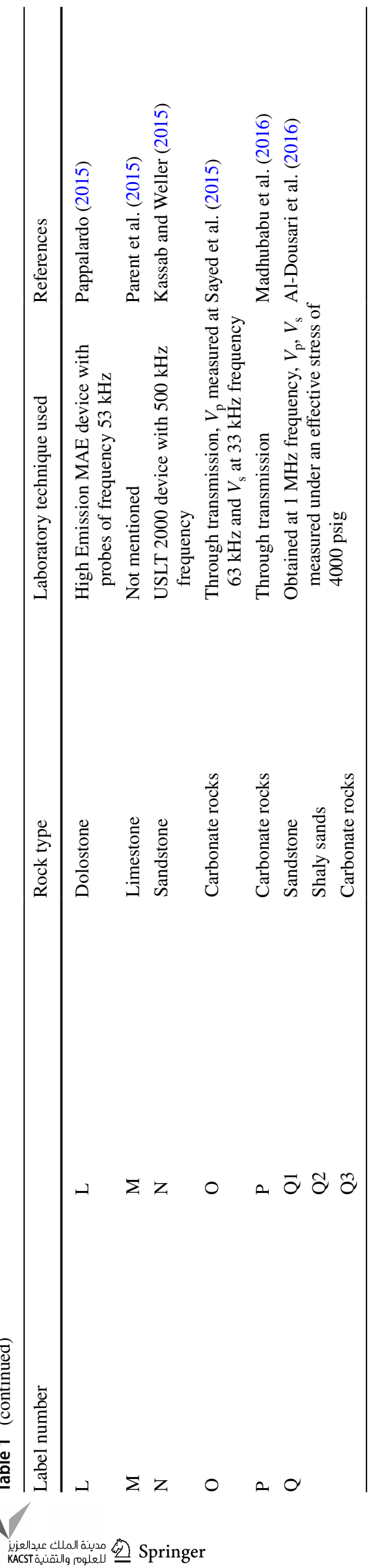

a common reference condition. Literature reported datasets generated from experimental measurements under stressed conditions were found to be derived under a range of stress values rather than a common standard value. As a result, it will be challenging to establish a common reference condition to correlate velocity values with petrophysical parameters. Moreover, samples might undergo mechanical alteration during pressurization under stressed conditions (alter sample microstructure) (Baechle et al. 2005). Therefore, the datasets developed under stressed conditions in laboratory have been excluded in this study.

The dataset comprises ultrasonic velocity measurements taken on different types of sandstone, mudstone, wackestone, limestone, marlstone, siltstone, conglomerate, claystone, marl, dolomite, shale, shaly sands and dolomitic limestone. Table 1 summarizes the details about the ultrasonic technique used for measuring $V_{\mathrm{p}}$ and $V_{\mathrm{s}}$ on different rock types by different researchers in their respective studies. During the process of data generation, it was found that there is scarcity in high-quality data, and hence, we have adopted a much-generalized approach in the consideration of geographic location, stratigraphy or geochronology of the rocks. The location of rocks from which the datasets have been generated for this particular study has been plotted in global map as shown in Fig. 1, and it indicates that datasets from all across the world have been taken for this study. The datasets used for the present study comprise $V_{\mathrm{p}}$ and $V_{\mathrm{s}}$ measured for various sedimentary rock samples in laboratory using different ultrasonic techniques as discussed in the subsequent paragraphs. However, it was found that experimental datasets available for measured values of shear wave velocity $\left(V_{\mathrm{s}}\right)$ are very rare. The reason for less datasets available for relationship between $V_{\mathrm{s}}$ and petrophysical properties in the literature may be due to several reasons including the fact that $V_{\mathrm{s}}$ is commonly calculated from $V_{\mathrm{p}}$ values that are already established method followed by researchers. Many empirical relations are suggested in the literature, such as, $V_{\mathrm{p}} / V_{\mathrm{s}}=1.65-2$ (Johnston and Christensen 1993), $V_{\mathrm{p}} / V_{\mathrm{s}}=1.5-1.7$ for quartzose sandstones, $V_{\mathrm{p}} / V_{\mathrm{s}}=1.9$ for pure limestones (Assefa et al. 2003). Hence, more studies were focused on relating $V_{\mathrm{p}}$ with the petrophysical properties such as porosity, permeability, density and clay content. By using the correlation between $V_{\mathrm{p}}$ and $V_{\mathrm{s}}\left(V_{\mathrm{p}} / V_{\mathrm{s}}\right.$ ratio $)$, the relationship between $V_{\mathrm{s}}$ and other petrophysical properties can be evaluated.

The different ultrasonic techniques, namely pulse-echo (Gaviglio 1989; Klimentos 1991; Assefa et al. 2003 etc.) and through transmission (Han et al. 1986; Yasar and Erdogan 2004; Kahraman and Yeken 2008; Kilic and Teymen 2008; Moradian and Behnia 2009; Sarkar et al. 2012; Madhubabu et al. 2016), were used by various researchers to measure the compressional (longitudinal) and shear (transverse) wave velocities in different rock samples. In pulse-echo technique, 


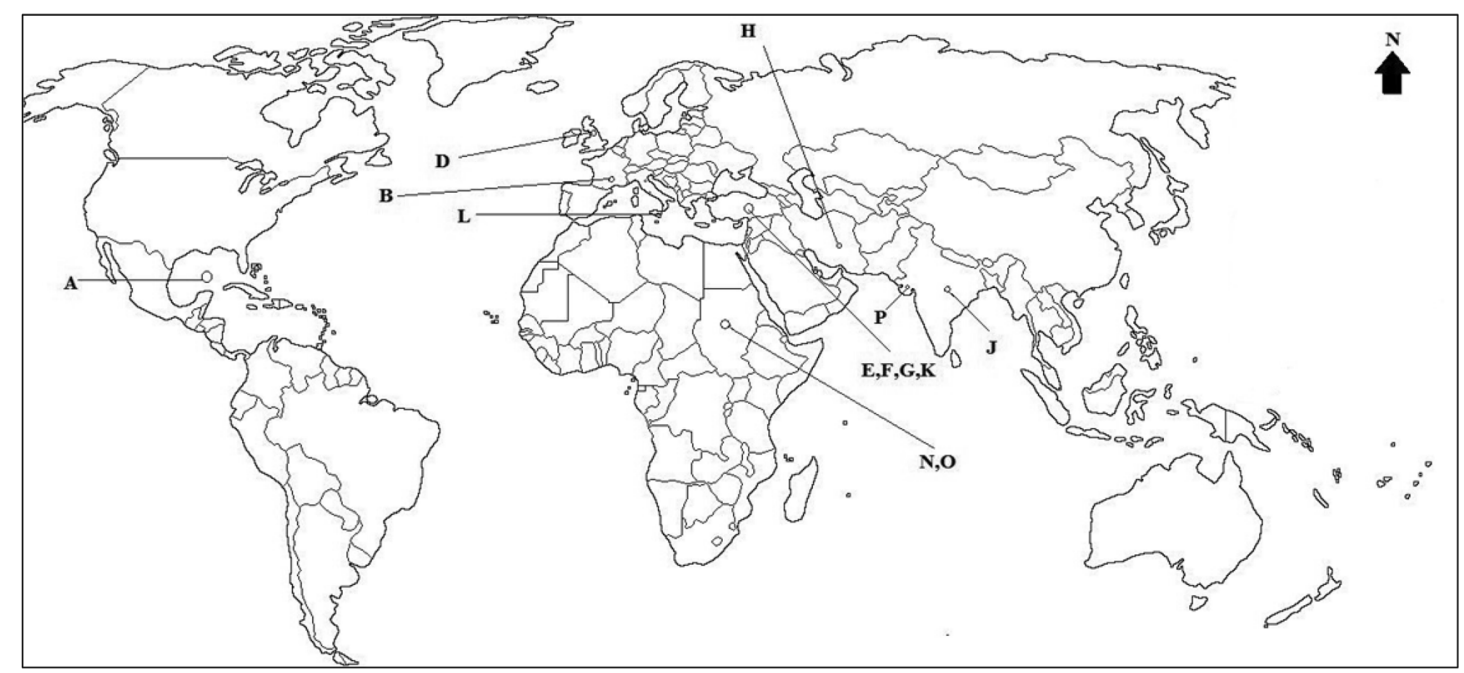

\section{LEGENDS}

A- Gulf of Mexico, B-Western Provence, France, D- Southern England, E- Adana, Turkey, F- Nigde, Kayseri, Konya \& Antalya, Turkey, G- Southern Anatolia, H- Iran,

J- Jutogh, Lower Shiwalik \& Lower Gondwana, India, K- Cebecikoy, Hereke, Akveren, Soguck \& Bakirkoy, Turkey, L- Peloritani Mounts, NE Sicily, N- Tushka, Egypt,

O- North Sinai, Egypt, P- Kutch, Gujrat, India

Fig. 1 Locations of study area appropriate to the sedimentary rock samples relevant to this study. A-Gulf of Mexico, B-Western Provence, France, D-Southern England, E-Adana, Turkey, FNigde, Kayseri, Konya and Antalya, Turkey, G-Southern Anatolia,

only one transducer (acting as both transmitter and receiver) is used for measuring velocity. For through transmission technique, a pair of transducers (one transmitter and one receiver) is used for measuring the velocity, and hence, the measured velocity $\left(V_{\mathrm{p}}\right.$ or $\left.V_{\mathrm{s}}\right)$ may not be affected by the type of measurement. The velocity of the rock samples has been determined either by using PUNDIT_-Portable Ultrasonic Non-destructive Digital Indicating Tester (Kilic and Teymen 2008; Karakul and Ulusay 2013; Yasar and Erdogan 2004; Moradian and Behnia 2009; Brotons et al. 2016), or by using a combination of pulse generator, transducers (transmitter and receiver) of varying frequencies $(54 \mathrm{kHz}$ to $1 \mathrm{MHz})$ and oscilloscope (Kahraman and Yeken 2008; Mueller 2013; Vilhelm et al. 2016). The Pundit consists of a pulse generator, transducers and an electronic counter for time interval measurements. Two different kinds of transducers have been used: a longitudinal transducer for measuring the P-wave velocity and a shear transducer for measuring the $\mathrm{S}$-wave velocity. The velocity values determined do not appear to be frequency dependent as long as the wavelength is significantly greater than the grain size (ISRM 1978; ASTM 2005). ISRM (1978) recommends the minimum lateral dimension should not be less than ten times the wavelength, while ASTM (2005) stipulates five times the wavelength.
H-Iran, J-Jutogh, Lower Shiwalik and Lower Gondwana, India, $\mathrm{K}$-Cebecikoy, Hereke, Akveren, Soguck and Bakirkoy, Turkey, LPeloritani Mounts, NE Sicily, N-Tushka, Egypt, O-North Sinai, Egypt, P-Kutch, Gujarat, India

Table 2 Standards for determination of different physical parameters of rock samples

\begin{tabular}{lll}
\hline Parameter & Standard & Formula \\
\hline Density & ISRM 1977, IS 13030-1991 & $\rho_{\text {dry }}=\frac{w_{\text {sat }} * \rho_{\text {fluid }}}{w_{\text {sat }}-w_{\text {sub }}}$ \\
Porosity & ISRM 1977, IS 13030-1991 & $n=\frac{w_{\text {sat }}-w_{\text {dry }}}{w_{\text {sat }}-w_{\text {sub }}}$ \\
P-wave velocity & ASTM D2845, IS 13311, Part 1: & $v=\frac{L}{t}$ \\
& 1992 & \\
\hline
\end{tabular}

Several test techniques and procedures have been employed in the literature for determining the different petrophysical properties. Table 2 shows the different standards/codes that have been used for the determination of different physical parameters, while Table 3 shows the instruments/tests used/conducted to derive datasets that are used for this study. We have not carried out any standardization or normalization on the datasets though it may be important to have one such as datasets generated from different methods or process. However, such an approach can propagate some bias in the analysis, and hence, we used original data as such.

To understand the relationship between compressional wave velocity $\left(V_{\mathrm{p}}\right)$ and porosity, a combined graphical 
Table 3 Instruments/tests used/conducted related to petrophysical properties to derive datasets relevant to this study

\begin{tabular}{llll}
\hline S. no. & Parameters analyzed & Instruments used & References \\
\hline 1 & Porosity & Helium gas porosimeter & Klimentos (1991) \\
& & Assefa et al. (2003) \\
& & Kahraman and Yeken (2008) \\
& & Kurtulus et al. (2016) \\
& Nitrogen gas permeameter & Madhubabu et al. (2016) \\
& & Klimentos (1991) \\
& Permeability & & Assefa et al. (2003) \\
& & Kassab and Weller (2015) \\
& Grain density & Selium pycnometer & Gegenhuber (2016) \\
& Mineralogy & XRD & Klimentos (1991) \\
& & Thin section studies & Klimentos (1991) \\
& & Karakul and Ulusay (2013) \\
& & & Pappalardo (2015) \\
& & & Madhubabu et al. (2016) \\
\hline
\end{tabular}

representation was generated from the given datasets of Kahraman and Yeken (2008), Kilic and Teymen (2008), Kurtulus et al. (2016), Kassab and Weller (2015) and Madhubabu et al. (2016). For datasets that are not in table format, graphical values were taken and plotted along with other datasets (Soroush et al. 2011; Pappalardo 2015; Parent et al. 2015; Sayed et al. 2015). Similarly, bulk density- $V_{\mathrm{p}}$ graph was plotted from values obtained by Kahraman and Yeken (2008), Moradian and Behnia (2009) and Kurtulus et al. (2016) and from graphical values given by Soroush et al. (2011), Parent et al. (2015) and Sayed et al. (2015). Water absorption $-V_{\mathrm{p}}$ relationship was obtained from dataset of Kahraman and Yeken (2008) and Kurtulus et al. (2016) and graphical values from Soroush et al. (2011). Permeability- $V_{\mathrm{p}}$ relationship was derived from studies conducted by Kassab and Weller (2015), Al-Dousari et al. (2016) and Sayed et al. (2015). Similarly, a combined graphical representation was obtained between shear wave velocity and different petrophysical parameters.

From the available data, a linear plot is considered to illustrate the relationship between the compressional velocities $(\mathrm{km} / \mathrm{s})$ with porosity $(\%)$, bulk density $\left(\mathrm{g} / \mathrm{cm}^{3}\right)$ and water absorption (\%). A semi-log plot is used between compressional wave velocities and permeability $(\mathrm{mD})$. It is important to understand the fact that a combined graphical representation of two parameters taken from studies conducted by various researchers across the world could lead to a general or universal trend that could nullify the effect of many other less important factors underlying in it. For this purpose, first we analyzed already existing trends or relationships in the form of equations (empirical relations) established by various researchers. From such analysis, it was found that empirical relationships derived by various researchers are applicable only to the datasets from which they were derived and are not useful as a general trend for extrapolation or interpolation. In another way, it means the correlation between the two parameters is poor. Although a general positive or negative trend is shown between the plotted parameters, it cannot be generalized in the form of a mathematical equation.

An effort is made to exclusively understand the relationship between $V_{\mathrm{p}}$ and porosity and the underlying effect of density on it. This is achieved by plotting velocity ratio (ratio of actual $V_{\mathrm{p}}$ and $V_{\mathrm{p}}$ obtained through proposed general trend for density) and porosity for those particular datasets for which density, porosity and compressional velocity were measured in the laboratory and available. These datasets include the studies of Kahraman and Yeken (2008), Soroush et al. (2011), Kurtulus et al. (2016) and Kassab and Weller (2015). This attempt is made to nullify the density effect by removing the effect of density from the porosity-velocity relationship.

\section{Results and discussion}

In the present study, we tried to analyze the change in the compressional and shear wave velocities of various sedimentary rock samples with respect to a number of petrophysical parameters such as porosity, bulk density, water saturation and permeability in ambient conditions. Among the datasets analyzed, datasets labeled as D, E, F, K, L, M, O, P represent carbonate rocks, while $\mathrm{A}, \mathrm{C}, \mathrm{N}$ represent sandstones as referred in Table 1. Datasets labeled as B, G, H, I, J, Q represent a combination of different rock types as summarized in Table 1. The relations between petrophysical properties and compressional and shear wave velocities for reservoir 

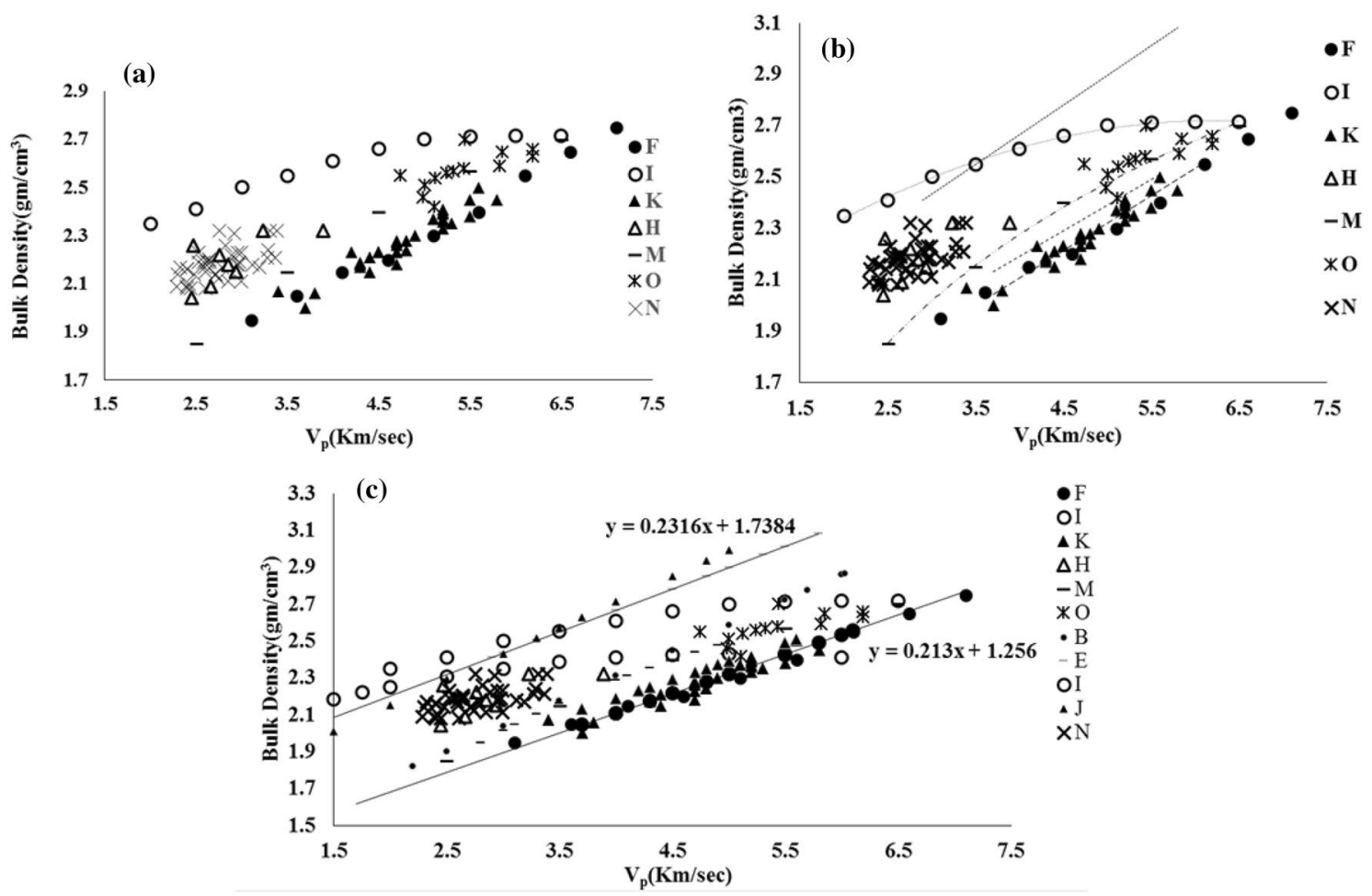

Fig. 2 Graphical representation of bulk density versus $V_{\mathrm{p}}$, a as reported by different researchers, $\mathbf{b}$ including empirical equations generated by different researchers (Label No. F, I, K, H, M, O, N are plotted as datasets empirical equations are plotted as lines). Remarks:

rocks have been analyzed and plotted, and all the empirical relations existing between them have been tabulated.

\section{Density and porosity}

One of the important petrophysical property analyzed in this study is bulk density. The bulk density takes into account the total volume (solid and pore space) of the rock specimen, including the natural voids. Several researchers, in their studies, have related $V_{\mathrm{p}}$ and $V_{\mathrm{s}}$ with the bulk density since these values are relatively easy to measure in field as well as in laboratory. A combined graphical representation of all the datasets (Fig. 2a) was generated to analyze the existing relationships and derive a general trend. The range of bulk density found from the graph is between 1.85 to $2.75 \mathrm{~g} / \mathrm{cm}^{3}$, and $V_{\mathrm{p}}$ ranges from 2 to $7.1 \mathrm{~km} / \mathrm{s}$. In general, it can be said that there is a linear relationship between $V_{\mathrm{p}}$ and bulk density for all rock types. Figure $2 b$ is an alternative representation of Fig. 2a along with empirical equations derived by various researchers relating bulk density and P-wave velocity. It is obvious from Fig. $2 \mathrm{~b}$ that all the empirical relationship given are valid to only the datasets from which it was derived and none of the existing empirical equations can be used as a general trend. Table 4 enlists all the empirical relations existing between density (bulk, saturated and dry
Label $\mathrm{M}$ is logarithmic variation, label I is polynomial variation, while the rest labels are linear varying as reported in their respective studies and, $\mathbf{c}$ including general trend derived from this study [where $Y$ is bulk density $\left(\mathrm{g} / \mathrm{cm}^{3}\right)$ and $X$ is $V_{\mathrm{p}}(\mathrm{km} / \mathrm{s})$ ]

density) and $V_{\mathrm{p}}$. We tried to fit a general trend for the entire dataset plotted, and Fig. 2c shows the general (proposed) linear trend bounding the maximum and minimum range of bulk density and compression wave velocity. General trends or global trends should be independent of the type of rock under study which is not applicable in this case. No clear trend is observed between bulk density and $V_{\mathrm{s}}$.

A detailed analysis of the relationship between $V_{\mathrm{p}}$ and porosity $(n)$ is presented in this study. For this purpose, three graphs have been plotted which highlight the correlation between $\mathrm{n}$ and $V_{\mathrm{p}}$. In Fig. 3a, only the datasets as reported by different researchers for their respective reservoir rock types have been plotted. In Fig. 3b, data representing the empirical equations as studied across the literature for the respective reservoir rocks, along with the datasets combined, are plotted. Figure $3 \mathrm{c}$ shows the general (proposed) trend, that is, an exponential decrease in porosity with an increase in $V_{\mathrm{p}}$. Such a type of general trend is independent of the type of rock under study which may be important for identifying an accurate relationship among the two parameters ( $n$ and $\left.V_{\mathrm{p}}\right)$. On closer scrutiny, the range of porosity found from the plotted graph is $0.40 \%$ to $37.81 \%$ for all the different rock types, for $V_{\mathrm{p}}$ varying between 1.47 and $6.75 \mathrm{~km} / \mathrm{s}$. However, the porosity values for carbonates and sandstones are scattered over the entire graph. Thus, it is clear that a negative

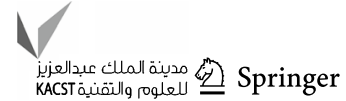


Table 4 Compilation of empirical equations derived for velocity $\left(V_{\mathrm{p}}, V_{\mathrm{s}}\right)$ and density as reported by various researchers

\begin{tabular}{|c|c|c|c|c|}
\hline S. no. & Parameters & Empirical relation & $\begin{array}{l}\text { Regression } \\
\text { coefficient }\left(R^{2}\right)\end{array}$ & References \\
\hline 1 & $\rho_{\text {dry }}(\mathrm{g} / \mathrm{cc})-V_{\mathrm{p}}(\mathrm{km} / \mathrm{s})$ & $V_{\mathrm{p}}=3.661 \rho_{\mathrm{dry}}-4.461$ & 0.78 & B \\
\hline 2 & $\rho_{\text {bulk }}(\mathrm{g} / \mathrm{cc})-V_{\mathrm{p}}(\mathrm{km} / \mathrm{s})$ & $V_{\mathrm{p}}=4.3183 \rho_{\text {bulk }}-7.5071$ & 0.81 & $\mathrm{E}$ \\
\hline 3 & $\rho_{\text {bulk }}(\mathrm{g} / \mathrm{cc})-V_{\mathrm{p}}(\mathrm{km} / \mathrm{s})$ & $\rho_{\text {bulk }}=0.213 V_{\mathrm{p}}+1.256$ & 0.821 & $\mathrm{~F}$ \\
\hline 4 & $\rho_{\text {bulk }}(\mathrm{g} / \mathrm{cc})-V_{\mathrm{p}}(\mathrm{m} / \mathrm{s})$ & $\rho_{\text {bulk }}=-2 X 10^{-8} V_{\mathrm{p}}^{2}+0.0002 V_{\mathrm{p}}+1.93$ & 0.71 & I \\
\hline 5 & $\rho_{\text {bulk }}(\mathrm{g} / \mathrm{cc})-V_{\mathrm{s}}(\mathrm{m} / \mathrm{s})$ & $\rho_{\text {bulk }}=-6 X 10^{-8} V_{\mathrm{s}}^{2}+0.0004 V_{\mathrm{s}}+1.94$ & 0.73 & I \\
\hline 6 & $\rho_{\text {dry }}(\mathrm{g} / \mathrm{cc})-V_{\mathrm{p}}(\mathrm{m} / \mathrm{s})$ & $\rho_{\text {dry }}=0.00028 V_{\mathrm{p}}+1.59$ & 0.934 & $\mathrm{~J}$ \\
\hline 7 & $\rho_{\text {dry }}(\mathrm{g} / \mathrm{cc})-V_{\mathrm{p}}(\mathrm{m} / \mathrm{s})$ & $\rho_{\text {dry }}=0.0003 V_{\mathrm{p}}+0.9815$ & 0.8794 & $\mathrm{~K}$ \\
\hline 8 & $\rho_{\text {sat }}(\mathrm{g} / \mathrm{cc})-V_{\mathrm{p}}(\mathrm{m} / \mathrm{s})$ & $\rho_{\mathrm{sat}}=1.8771 e^{5 E-0.5 V_{\mathrm{p}}}$ & 0.8182 & $\mathrm{~K}$ \\
\hline 9 & $\rho_{\text {bulk }}(\mathrm{g} / \mathrm{cc})-V_{\mathrm{p}}(\mathrm{m} / \mathrm{s})$ & $\rho_{\text {bulk }}=0.0002 V_{\mathrm{p}}+1.339$ & 0.8996 & $\mathrm{~K}$ \\
\hline 10 & $\rho_{\text {bulk }}\left(\mathrm{kg} / \mathrm{m}^{3}\right)-V_{\mathrm{p}}(\mathrm{m} / \mathrm{s})$ & $\rho_{\text {bulk }}=946 \ln \left(V_{\mathrm{p}}\right)-5561$ & 0.84 & M \\
\hline
\end{tabular}

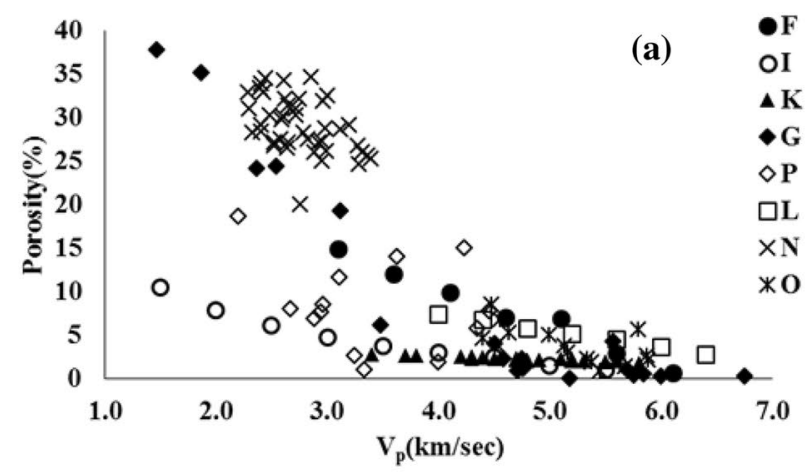

40
35
30
25
15
10
5

Fig. $3 V_{\mathrm{p}}$ versus porosity a as reported by differes
including empirical relationships generated by various researchers (datasets plotted as symbols while lines represent empirical equation)

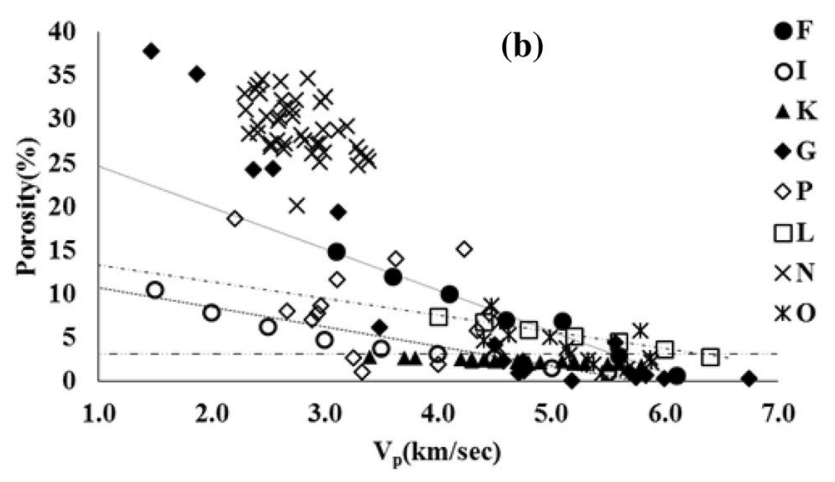

(c)

\section{F \\ OI \\ $\mathrm{K}$ \\ $\square \mathbf{L}$ \\ $\times \mathbf{N}$ \\ xo 0}




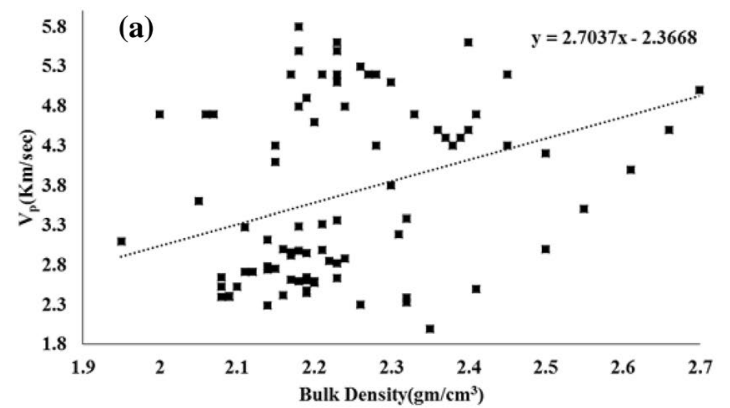

Fig. $4 V_{\mathrm{p}}$ versus bulk density $\mathbf{a}$ as reported by different researchers (Kahraman and Yeken 2008; Soroush et al. 2011; Kurtulus et al. 2016; Kassab and Weller 2015) along with general trend used to calculate $V_{\mathrm{p}}$ (density) in this study [where $Y$ axis is $V_{\mathrm{p}}(\mathrm{km} / \mathrm{s})$ and $X$ is

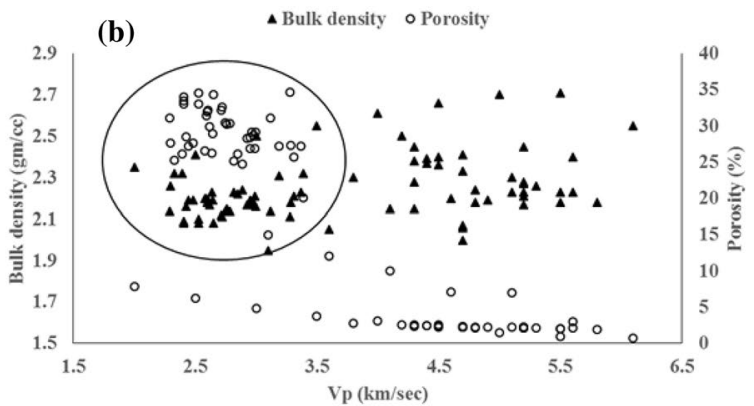

bulk density $\left.\left(\mathrm{g} / \mathrm{cm}^{3}\right)\right]$, and $\mathbf{b} V_{\mathrm{p}}$ versus porosity and bulk density (the datasets falling in the circle show a porosity value more than $20 \%$ with a low bulk density and comparatively lower $V_{\mathrm{p}}$ values
Table 5 Compilation of empirical equations derived for velocity $\left(V_{\mathrm{p}}, V_{\mathrm{s}}\right)$ and porosity as reported by various researchers

\begin{tabular}{lllll}
\hline S. no. & Parameters & Empirical relation & $\begin{array}{l}\text { Regression coef- } \\
\text { ficient }\left(R^{2}\right)\end{array}$ & References \\
\hline 1 & $n$ (fraction) $-V_{\mathrm{p}}(\mathrm{km} / \mathrm{s})$ & $V_{\mathrm{p}}=5.02-5.63 n$ & 0.840 & $\mathrm{~A}$ \\
2 & $n($ fraction$)-V_{\mathrm{s}}(\mathrm{km} / \mathrm{s})$ & $V_{\mathrm{s}}=3.03-3.78 n$ & 0.754 & $\mathrm{~A}$ \\
3 & $n(\%)-V_{\mathrm{p}}(\mathrm{m} / \mathrm{s})$ & $V_{\mathrm{p}}=5317-89 n$ & 0.46 & $\mathrm{D}$ \\
4 & $n(\%)-V_{\mathrm{s}}(\mathrm{m} / \mathrm{s})$ & $V_{\mathrm{s}}=2844-49 n$ & 0.44 & $\mathrm{D}$ \\
5 & $n(\%)-V_{\mathrm{p}}(\mathrm{km} / \mathrm{s})$ & $n=-4.733 V_{\mathrm{p}}+29.377$ & 0.844 & $\mathrm{~F}$ \\
6 & $n(\%)-V_{\mathrm{p}}(\mathrm{m} / \mathrm{s})$ & $n=-7.415 \ln \left(V_{\mathrm{p}}\right)+64.96$ & 0.63 & $\mathrm{I}$ \\
7 & $n(\%)-V_{\mathrm{s}}(\mathrm{m} / \mathrm{s})$ & $n=-8.61 \ln \left(V_{\mathrm{s}}\right)+69.45$ & 0.60 & $\mathrm{I}$ \\
8 & $n(\%)-V_{\mathrm{p}}(\mathrm{km} / \mathrm{s})$ & $n=15.24-1.899 V_{\mathrm{p}}$ & 0.74 & $\mathrm{~L}$ \\
9 & $n(\%)-V_{\mathrm{p}}(\mathrm{km} / \mathrm{s})$ & $n^{\prime}=6.377-0.719 V_{\mathrm{p}}$ & 0.60 & $\mathrm{~L}$ \\
10 & $n(\%)-V_{\mathrm{p}}(\mathrm{m} / \mathrm{s})$ & $n=-0.004 V_{\mathrm{p}}+3.1465$ & 0.85 & $\mathrm{~K}$ \\
\hline
\end{tabular}

various researchers from their datasets, and after plotting these datasets, it is evident that those empirical relationships are not valid in a general form and a one-to-one correlation is not possible. Hence, an attempt is made to establish a one-to-one relationship by removing the influence of density factor. The sole purpose of plotting Fig. 5b is to understand the direct relationship between $V_{\mathrm{p}}$ and porosity by removing the density effect. Figure 5c) shows the combined representation of porosity with respect to compressional wave velocity measured ( $V_{\mathrm{p}}$ ) to the ratio between $V_{\mathrm{p}}$ and $V_{\mathrm{p}}$ (density) calculated from the general trend observed between bulk density and $V_{\mathrm{p}}$. Previous studies provide limited information about how density has an effect on porosity and velocity. The plot so generated shows a decrease in porosity with an increase in $V_{\mathrm{p}}$.

A detailed analysis on the relationship between $V_{\mathrm{s}}$ and bulk density is not possible due to scarcity of data. Figure 6 depicts a graphical representation of bulk density with respect to $V_{\mathrm{s}}$ obtained with a poorly fitted general trend derived from studies conducted by three different studies, namely Moradian and Behnia (2009), Soroush et al. (2011) and Sayed et al. (2015). The range of bulk density found from the plotted graph is 2.04-2.73 $\mathrm{g} / \mathrm{cc}$ for all the different rock types, for $V_{\mathrm{s}}$ varying between 1.2 and $3.1 \mathrm{~km} / \mathrm{s}$. Soroush et al. (2011) (legend I) in his study suggested a quadratic (increasing trend) correlation between both the parameters, which is also evident from Fig. 6. In general, $V_{\mathrm{s}}$ increases with an increase in bulk density. However, in totality, a scattered plot is observed but cannot be generalized due to data scarcity.

\section{Water absorption and saturating fluid}

The plotted graph, as well as the results reported in the literature, indicates that there is a negative correlation between $V_{\mathrm{p}}$ and water absorption. Thus, $V_{\mathrm{p}}$ may be used as an objective parameter for estimation of water absorption characteristic (Kurtulus et al. 2016). From the graph as shown in Fig. 7, the range of water absorption found from graph is $0.1-6.45 \%$ and $V_{\mathrm{p}}$ range is $2-6.1 \mathrm{~km} / \mathrm{s}$. However, water absorption being an important rock index depends on mineralogy and porosity of rock (Soroush et al. 2011). Table 6 shows the empirical relations between water absorption and $V_{\mathrm{p}}$ and $V_{\mathrm{s}}$. 

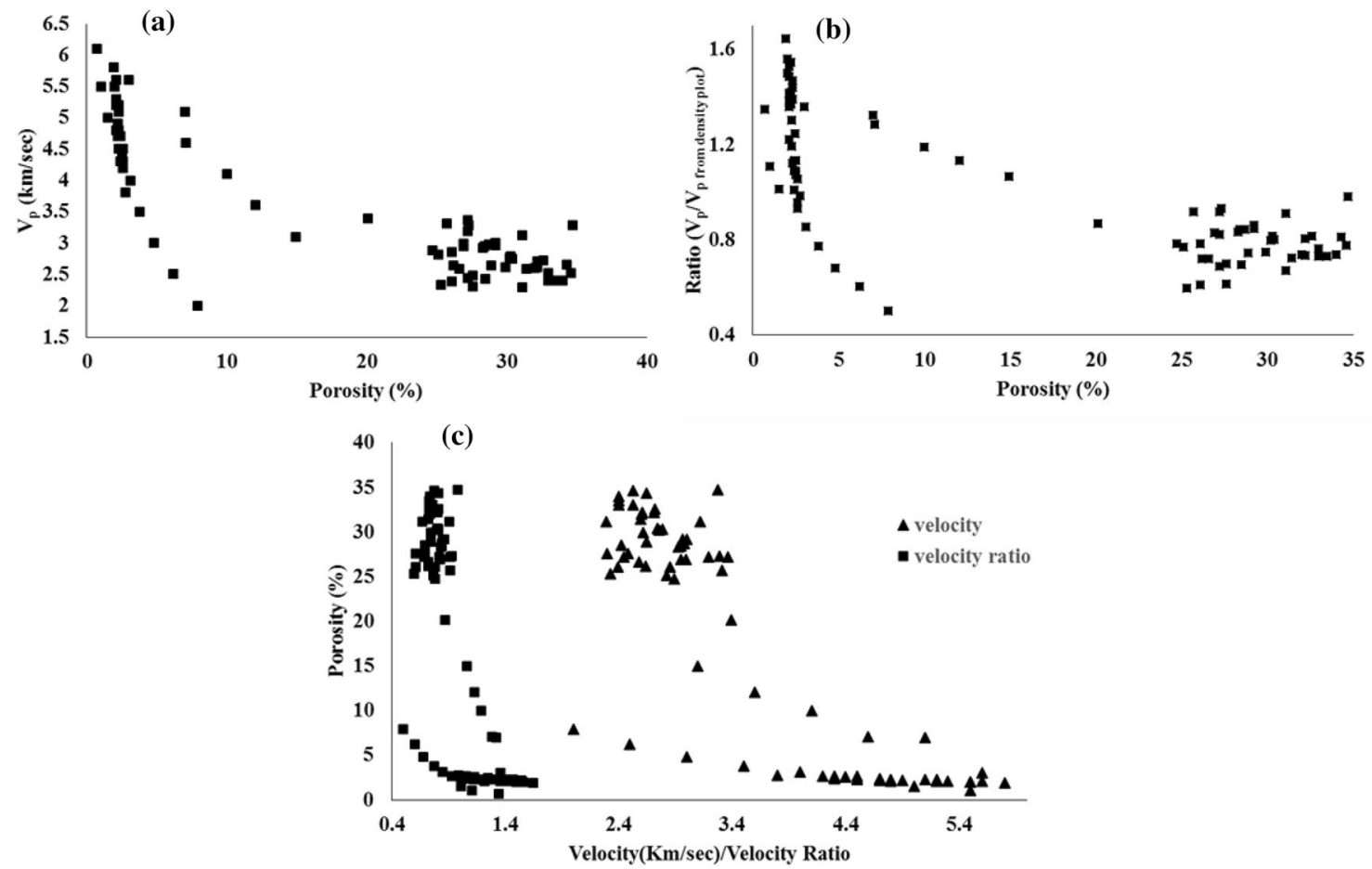

Fig. $5 V_{\mathrm{p}}$ versus porosity, a as reported by different researchers (Kahraman and Yeken 2008; Soroush et al. 2011; Kurtulus et al. 2016; Kassab and Weller 2015) [where $Y$ is $V_{\mathrm{p}}(\mathrm{km} / \mathrm{s})$ and $X$ is porosity (\%)], b including ratio of actual $V_{\mathrm{p}}$ and $V_{\mathrm{p}}$ obtained from density plot, and porosity as reported by different researchers (Kahraman and
Yeken 2008; Soroush et al. 2011; Kurtulus et al. 2016; Kassab and Weller 2015), c including $V_{\mathrm{p}}$ and ratio of actual $V_{\mathrm{p}}$ and $V_{\mathrm{p}}$ obtained from density plot, with porosity as reported by different researchers (Kahraman and Yeken 2008; Soroush et al. 2011; Kurtulus et al. 2016; Kassab and Weller 2015)
Fig. $6 V_{\mathrm{s}}$ (shear wave velocity) versus bulk density as reported by different researchers

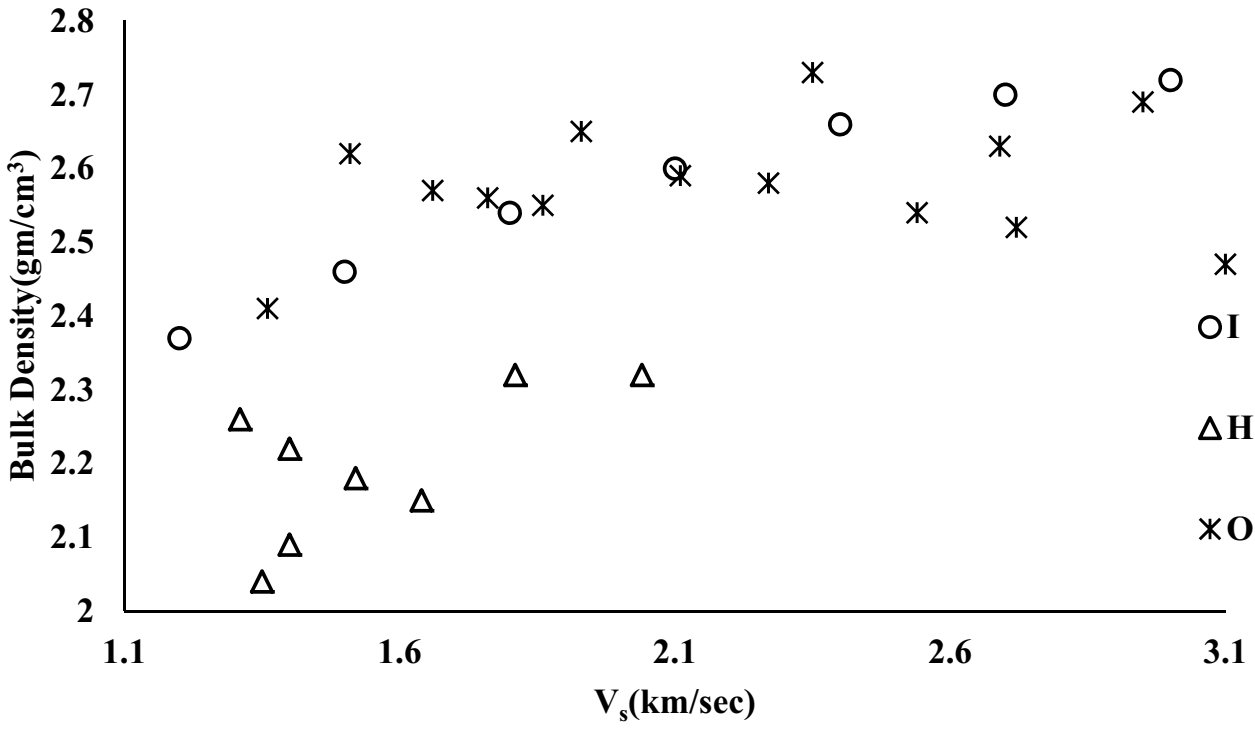

Also, the type of the saturating fluid also has an effect on the compressional and shear wave velocities. A rock may be saturated with water, oil, brine or gas. The velocity of $\mathrm{P}$-wave is highest for brine saturated, intermediate for kerosene and lowest for the dry rock at all pressures, whereas the shear wave velocities are highest for the dry rock and lowest for the brine saturated rock. Moreover, the effect of saturating fluid is more in compressional velocities than in shear wave velocities (Toksoz et al. 1976). 
Fig. $7 V_{\mathrm{p}}$ versus water absorption as reported by different researchers
Table 6 Compilation of empirical equations derived for velocity $\left(V_{\mathrm{p}}, V_{\mathrm{s}}\right)$ and water absorption as reported by various researchers

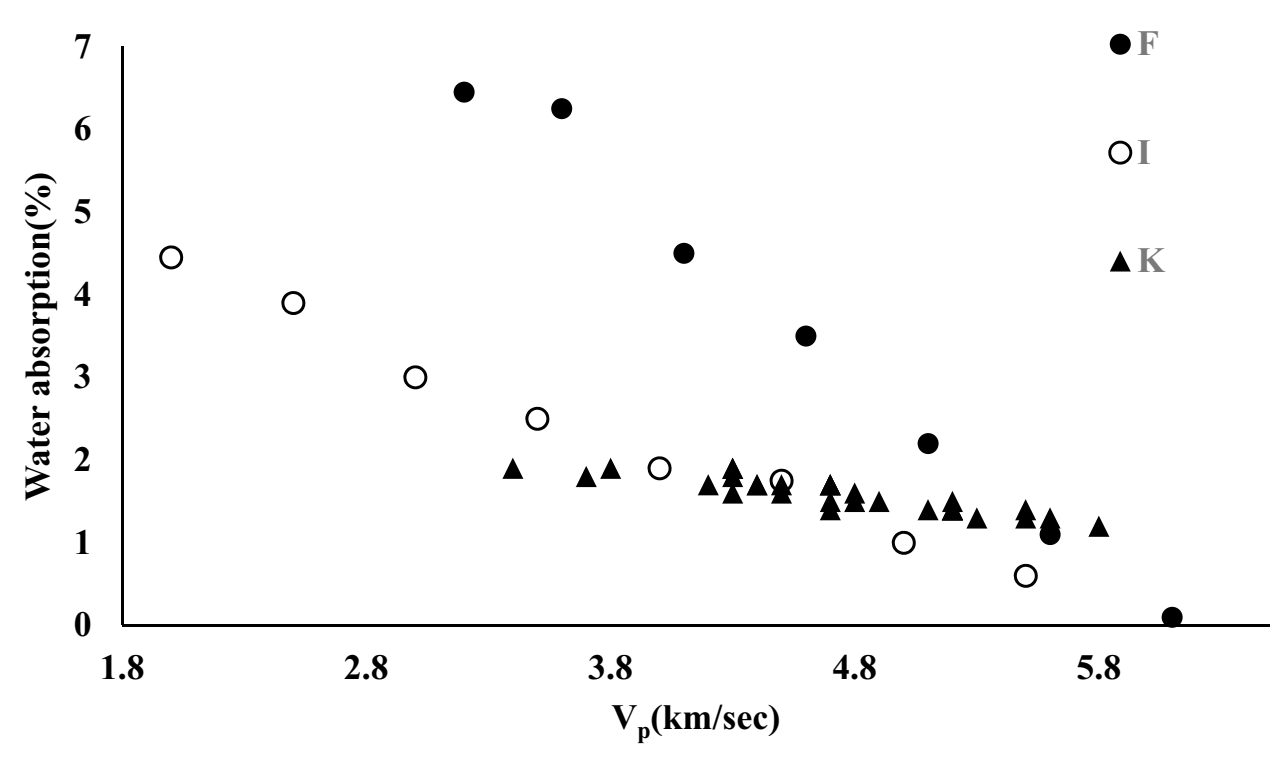

\begin{tabular}{lllll}
\hline S. no. & Parameters & Empirical relation & $\begin{array}{l}\text { Regression coef- } \\
\text { ficient }\left(R^{2}\right)\end{array}$ & Reference \\
\hline 1 & $W_{\mathrm{a}}(\%)-V_{\mathrm{p}}(\mathrm{km} / \mathrm{s})$ & $W_{\mathrm{a}}=-2.248 V_{\mathrm{p}}+13.76$ & 0.90 & $\mathrm{~F}$ \\
2 & $W_{\mathrm{a}}(\%)-V_{\mathrm{p}}(\mathrm{m} / \mathrm{s})$ & $W_{\mathrm{a}}=-4.184 \ln \left(V_{\mathrm{p}}\right)+36.56$ & 0.81 & $\mathrm{I}$ \\
3 & $W_{\mathrm{a}}(\%)-V_{\mathrm{s}}(\mathrm{m} / \mathrm{s})$ & $W_{\mathrm{a}}=-4.390 \ln \left(V_{\mathrm{s}}\right)+35.28$ & 0.75 & $\mathrm{I}$ \\
\hline
\end{tabular}

\section{Permeability}

Very few studies have been conducted considering the effect of permeability on the compressional and shear wave velocity. Kassab and Weller (2015) illustrated that there is no clear trend between $V_{\mathrm{p}}$ and permeability, while Sayed et al. (2015) observed a weak relationship between the two. Also, Al-Dousari et al. (2016) observed a weak relation between the two properties measured under an effective stress of 4000 psig. But, Klimentos (1991) through his study under confining pressure indicated that there is a minor increasing trend of P-wave velocity with increasing permeability, thereby suggesting that the effect of permeability alone is negligible. In other words, the effect of permeability on P-wave velocity is minimal compared to that of porosity and clay content. However, it is to be noted that there is an interdependency of permeability with porosity and density and a combined analysis is required to understand the undercovered trend of permeability clearly. In other words, the misleading permeability-velocity relationship may be attributed to the influence of clay content-velocity relationship. From the plotted semi-log graph as shown in Fig. 8, the range of permeability found is $1.15-4969.19 \mathrm{mD}$ and $V_{\mathrm{p}}$ range is $3.12-6.33 \mathrm{~km} / \mathrm{s}$.

\section{Clay content}

Most of the researchers have investigated the relationship between clay content and $V_{\mathrm{p}}$ and $V_{\mathrm{s}}$ under confining pressures (Han et al. 1986; Klimentos 1991) and observed that there is a clear linear trend of decreasing P-wave velocity with an increase in the clay content in both poor and wellconsolidated rock samples. The reason for the effect being the higher compressibility of the clay minerals significantly affects the ultrasonic waves traveling through the rocks. Even small amount of clay content may have a larger effect on decreasing the velocity since clays can alter the petrophysical properties either by reducing the pore size or by increasing the specific surface area. However, Al-Dousari et al. (2016) studied the relationship between clay content and $V_{\mathrm{p}}$ measured at an effective stress of $4000 \mathrm{psi}$ on sandstone/shaly sands/carbonate rocks and observed a scattering of data indicating no clear trend. Hence, it can be concluded that clay content has a dominant effect on $V_{\mathrm{p}}$ and a small variation in its amount can result in a change in $V_{\mathrm{p}}$. There is a lack of study on the influence of clay content on $V_{\mathrm{p}}$ as well as $V_{\mathrm{s}}$ under ambient condition. It is predictable that $V_{\mathrm{p}}$ and $V_{\mathrm{s}}$ will be affected by the amount of clay present in the rock sample. The effect of clay can already be sighted by its effect in other petrophysical parameters, especially density, porosity and permeability. 
Fig. $8 V_{\mathrm{p}}$ versus permeability as reported by different researchers

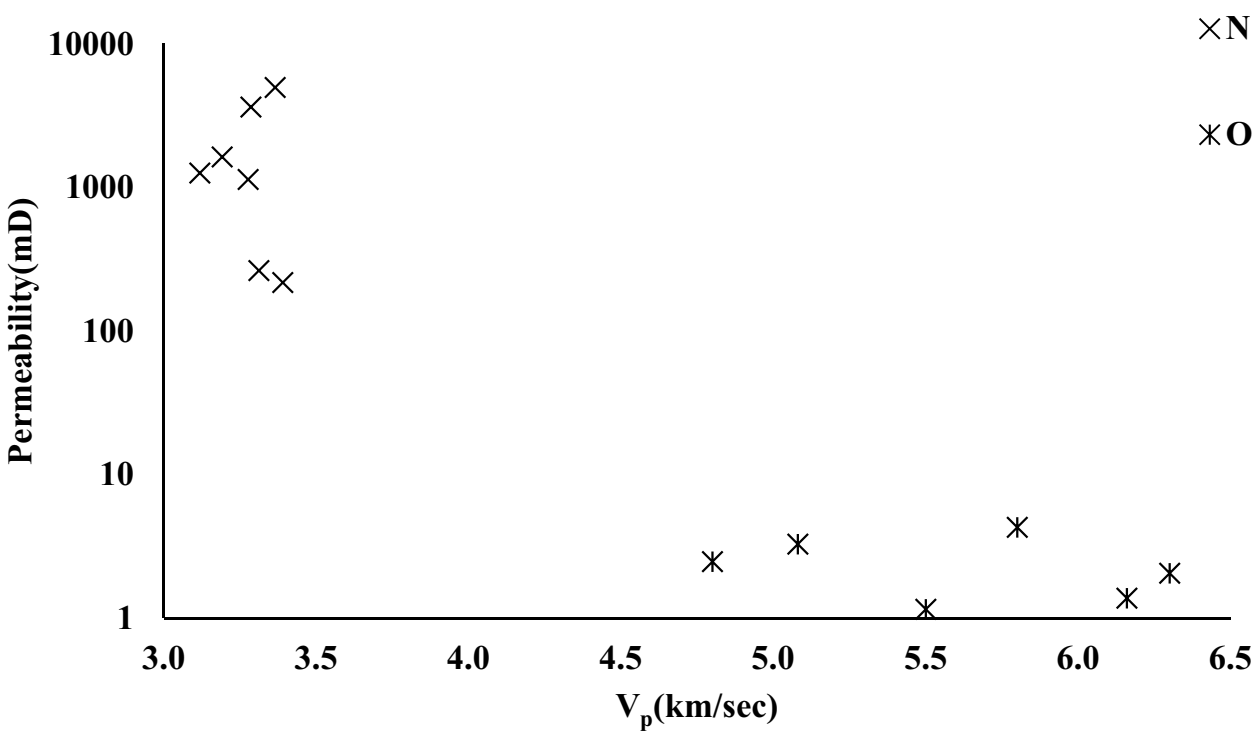

\section{Conclusions}

In this detailed study on the relationships between the petrophysical properties and the compressional and shear wave velocities based on datasets measured under laboratory condition, it is clear that trends do exist, but the prediction is difficult. The empirical relationships derived by various researchers are valid only to the particular dataset for which the relationship was derived. An effort is made to propose a general trend (global trends) for Porosity versus $V_{\mathrm{p}}$ and Bulk density versus $V_{\mathrm{p}}$, which is independent of the type of datasets. The influence of other factors like mineralogy, rock framework, pore geometry has not been studied by the researchers in their respective studies. The factors such as chemical and mineralogical composition, the structure and geometry of the pores (their orientation, distribution and packaging), the grain size, the type of pore filling minerals and the cementing material also need to be taken care of while assessing the relationship between the different petrophysical properties with compressional and shear wave velocities. It is very clear from the analysis that there exists an interdependence among various petrophysical parameters that affect the compressional and shear wave velocities. Such type of a combined study incorporating the influence of geological factors on the petrophysical and seismic properties is lacking, and this kind of analysis needs to be done for future research to depict an actual relationship among the properties. Sonic velocity modeling will be more accurate by incorporating mineralogical and petrophysical effects in combination rather than separately. An accurate reservoir description can only be achieved by proper integration of geological, petrophysical and engineering data.
Open Access This article is distributed under the terms of the Creative Commons Attribution 4.0 International License (http://creativeco mmons.org/licenses/by/4.0/), which permits unrestricted use, distribution, and reproduction in any medium, provided you give appropriate credit to the original author(s) and the source, provide a link to the Creative Commons license, and indicate if changes were made.

\section{References}

Al-Dousari M, Garrouch AA, Al-Omair O (2016) Investigating the dependence of shear wave velocity on petrophysical parameters. J Pet Sci Eng 146:286-296

Assefa S, Mccann C, Sothcott J (2003) Velocities of compressional and shear waves in limestones. Geophys Prospect 51:1-13

ASTM D 2845-08 (2005) Standard test method for laboratory determination of pulse velocities and ultrasonic elastic constants of rock

Baechle GT et al (2005) Changes of shear moduli in carbonate rocks: implications for Gassmann applicability. Lead Edge 24(5):507-510

Brotons V, Tomas R, Ivorra S, Grediaga A, Martınez J, Benavente D, Gomez M (2016) Improved correlation between the static and dynamic elastic modulus of different types of rocks. Mater Struct 49:3021-3037

Chengzao J (2017) Breakthrough and significance of unconventional oil and gas to classical petroleum geology theory. Pet Explor Dev 44(1): $1-10$

Dvorkin J, Gutierrez M, Grana D (2014) Seismic reflections of rock properties. Cambridge University Press, Cambridge

Gaviglio P (1989) Longitudinal waves propagation in a limestone: the relationship between velocity and density. Rock Mech Rock Eng 22(4):299-306

Gegenhuber N (2016) Interpretation of elastic properties for magmatic and metamorphic rock types. Int J Rock Mech Min Sci 88:44-48

Han D, Nur A, Morgan D (1986) Effects of porosity and clay content on wave velocities in sandstones. Geophysics 51:2093-2107

IS: 13030 (1991) Method of test for laboratory determination of water content, porosity, density and related properties of rock material. Bureau of Indian Standards, New Delhi

ISRM (1977) Suggested methods for determining water content, porosity, density, absorption and related properties and swelling 
and slake-durability index properties. Int J Rock Mech Min Sci Geomech Abstr 16:141-156

ISRM (1978) Suggested method for determining sound velocity. Int J Rock Mech Min Sci Geomech Abstr 15:53-58

Johnston JE, Christensen NI (1993) Compressional to shear velocity ratios in sedimentary rocks. Int J Rock Mech Min Sci Geomech Abstr 30(7):751-754

Kahraman S (2007) The correlations between the saturated and dry P-wave velocity of rocks. Ultrasonics 46(4):341-348

Kahraman S, Yeken T (2008) Determination of physical properties of carbonate rocks from P-wave velocity. Bull Eng Geol Environ $67: 277-281$

Karakul H, Ulusay R (2013) Empirical correlations for predicting strength properties of rocks from p-wave velocity under different degrees of saturation. Rock Mech Rock Eng 46:981-999

Kassab MA, Weller A (2015) Study on P-wave and S-wave velocity in dry and wet sandstones of Tushka region, Egypt. Egypt J Pet 24(1):1-11

Kilic A, Teymen A (2008) Determination of mechanical properties of rocks using simple methods. Bull Eng Geol Environ 67(2):237-244

Klimentos T (1991) The effects of porosity-permeability-clay content on the velocity of compressional waves. Geophysics 56:1930-1939

Kurtulus C, Cakir S, Yogurtcuoglu AC (2016) Ultrasound study of limestone rock physical and mechanical properties. Soil Mech Found Eng 52(6):27-31

Madhubabu N, Singh PK, Kainthola A, Mahanta B, Tripathy A, Singh TN (2016) Prediction of compressive strength and elastic modulus of carbonate rocks. Measurement 88:202-213

McDowell PW, Millett N (1984) Surface ultrasonic measurement of longitudinal and transverse wave velocities through rock samples. Int J Rock Mech Min Sci Geomech Abstr 21:223-227

Moradian ZA, Behnia M (2009) Predicting the uniaxial compressive strength and static Young's modulus of intact sedimentary rocks using the ultrasonic test. Int J Geomech 9(1):14-19

Mueller HJ (2013) Measuring the elastic properties of natural rocks and mineral assemblages under Earth's deep crustal and mantle conditions. J Geodyn 71:25-42

Pappalardo G (2015) Correlation between P-wave velocity and physical-mechanical properties of intensely jointed dolostones, Peloritani Mounts, NE Sicily. Rock Mech Rock Eng 48:1711-1721
Pappalardo G, Mineo S (2016) Geotechnical characterization of limestones employed for the reconstruction of a UNESCO world heritage Baroque monument in southeastern Sicily (Italy). Eng Geol 212:86-97

Parent T, Domede N, Sellier A, Mouatt L (2015) Mechanical characterization of limestone from sound velocity measurement. Int J Rock Mech Min Sci 79:149-156

Sarkar K, Vishal V, Singh TN (2012) An empirical correlation of index geomechanical parameters with the compressional wave velocity. Geotech Geol Eng 30:469-479

Sayed NA, El Abuseda H, Kassab MA (2015) Acoustic wave velocity behavior for some Jurassic carbonate samples. J Afr Earth Sci 111:14-25

Sharma PK, Singh TN (2008) A correlation between P-wave velocity, impact strength index, slake durability index and uniaxial compressive strength. Bull Eng Geol Environ 67:17-22

Soroush H, Qutob H, Oil W, Me T (2011) Evaluation of rock properties using ultrasonic pulse technique and correlating static to dynamic elastic constants. In: 2nd south Asian geoscience conference and exhibition, GEOIndia 2011, Greater Noida, New Delhi, India

Toksoz MN, Cheng CH, Timur A (1976) Velocities of seismic waves in porous rocks. Geophysics 41:621-645

Vilhelm J, Ivankina T, Lokají T, Rudajev V (2016) Comparison of laboratory and field measurements of $\mathrm{P}$ and $\mathrm{S}$ wave velocities of a periodite rock. Int J Rock Mech Min Sci 88:235-241

Yasar E, Erdogan Y (2004) Correlating sound velocity with the density, compressive strength and Young's modulus of carbonate rocks. Int J Rock Mech Min Sci 41(2004):871-875

Yu C, Ji S, Li Q (2016) Effects of porosity on seismic velocities, elastic moduli and Poisson's ratios of solid materials and rocks. J Rock Mech Geotech Eng 8:35-49

Publisher's Note Springer Nature remains neutral with regard to jurisdictional claims in published maps and institutional affiliations. 